\title{
Safety and Efficacy of Once-Daily Gastroretentive Gabapentin in Patients with Postherpetic Neuralgia Aged 75 Years and Over
}

\author{
Anita Gupta $\cdot$ Sean Li
}

Published online: 26 October 2013

(c) The Author(s) 2013. This article is published with open access at Springerlink.com

\begin{abstract}
Background Treatment of postherpetic neuralgia (PHN) is more complicated in elderly patients, and multiple daily dosing, complex titration, and high incidences of adverse events can be limiting for many pharmacological treatment options.

Objective The aim of this study was to determine whether the efficacy and tolerability of once-daily gastroretentive gabapentin (G-GR) is similar between elderly patients ( $\geq 75$ years) and younger patients ( $<75$ years).

Methods Data from two phase III, placebo-controlled studies of $1,800 \mathrm{mg}$ G-GR once daily with dinner in patients with PHN were integrated and analyzed by age subgroups ( $<75$ years, $n=527$; $\geq 75$ years, $n=192$ ). Efficacy assessments at endpoint (week 10) included baseline-adjusted change in average daily pain (ADP) and average daily sleep interference (SIS) scores, the proportion of responders ( $\geq 30 \%$ pain reduction), and the proportion of patients feeling "Much" or "Very Much" improved on the Patient Global Impression of Change (PGIC).

Results Compared with placebo, patients in both age subgroups treated with G-GR (placebo/G-GR) had greater reductions in mean ADP $(\geq 75:-21.9 /-34.2 \%$, $p=0.0348 ;<75:-29.9 /-38.3 \%, p=0.0079)$ and SIS
\end{abstract}

\footnotetext{
A. Gupta $(\bowtie)$

University Pain Institute, Division of Pain Medicine \& Regional Anesthesiology, Department of Anesthesiology and Perioperative Medicine, Drexel University College of Medicine, 245 North 15th Street, New College Building, MS 310, Philadelphia, PA 19102, USA

e-mail: anita.gupta@drexelmed.edu

S. Li

Premier Pain Centers, Shrewsbury, NJ 07702, USA
}

$(\geq 75:-1.3 /-2.4, p=0.0017 ;<75:-1.8 /-2.7, p<0.0001)$, more patients were responders $(\geq 75$ : $30.4 / 52.0 \%$, $p=0.0025 ;<75: 45.0 / 54.7 \%, p=0.0265)$, and more felt "Much" or "Very Much" improved on the PGIC ( $\geq 75: 20.7 /$ $35.0 \%, p=0.0272 ;<75: 33.6 / 44.9 \%, p=0.0077)$. The most common (placebo/G-GR) adverse events (AEs) were dizziness $(\geq 75: 3.3 / 12.0 \% ;<75: 1.8 / 10.4 \%)$, nausea $(\geq 75$ : 1.0/5.4\%; $<75: 2.9 / 4.2 \%)$, and somnolence ( $\geq 75: 0 / 5.0 \%$; $<75: 3.7 / 4.2 \%$ ). For all patients, AEs rapidly decreased to low steady levels after 4-5 weeks of treatment. The incidence of serious AEs was low and they were reported more frequently in the placebo than in the G-GR group.

Conclusions Therapy with once-daily G-GR was as effective for treating pain associated with PHN in elderly patients as it was in younger patients. G-GR was well tolerated, and the incidence of the most common AEs did not appear to be age related.

\section{Background}

Postherpetic neuralgia (PHN), a painful complication of herpes zoster (HZ) or shingles, is characterized by the presence of persistent pain 1-6 months following resolution of acute $\mathrm{HZ}$ (i.e., after healing of the associated skin rash) [13]. The individual lifetime risk for developing $\mathrm{HZ}$ and PHN varies slightly by country, but age-specific rates uniformly show that incidences increase sharply after 50 years of age, and that the elderly are most frequently affected. Approximately 8 in 1,000 people aged $\geq 60$ years, and 10.5 in 1,000 people aged $\geq 80$ years are diagnosed with $\mathrm{HZ}$ each year $[4$, 5]. In patients who have had HZ, PHN develops in approximately $18 \%$ of patients $\geq 60$ years and $30 \%$ of those $\geq 80$ years [6-8]. The prevalence of PHN is only expected to increase over time as the population ages [9]. According to 
the 2013 World Population Data Base, 846 million people $(8 \%)$ are $\geq 65$ years and 18.5 million $(3 \%)$ are $\geq 75$ years [10]. The World Population projection estimates that, by $2050,17 \%$ of the population will be $\geq 65$ years and $8 \%$ will be $\geq 75$ years [10].

In addition to having a higher prevalence of PHN, elderly patients often have chronic co-morbid conditions (e.g., osteoarthritis and rheumatologic disease) [11], with a prevalence of multimorbidity reported in as many as $93 \%$ of 45-64 year olds and $98 \%$ of those $>65$ years [12]. Individuals with multimorbidity are at increased risk for longer hospitalizations, polypharmacy, and higher healthcare costs. Among community-dwelling individuals, $37 \%$ of men and $36 \%$ of women aged $75-85$ years used at least five prescription medications concurrently [13]. When prescribing pain medication for this elderly population, drug-drug interactions, as well as drug-disease interactions, need to be taken into account. Adverse reactions have indeed been shown to be more common among older adults and to have greater potential for causing harm [14, 15]. Furthermore, a steady decline of homeostatic mechanisms and function of important organ systems (including hepatic, renal, cardiac, and central nervous system) associated with aging leads to clinically important changes in drug absorption, metabolism, volume of distribution, plasma concentration, and drug bioavailability in the elderly [16]. Therefore, although pain management in older patients generally follows the same principle as in younger patients, the approach often requires modifications because of co-morbidities and/or physiological changes associated with aging that alter the pharmacodynamics and pharmacokinetics of drugs.

Agents from four therapeutic categories have demonstrated efficacy in clinical trials for relieving the pain associated with PHN. These include tricyclic antidepressants, anticonvulsants, opioids, and topical anesthetics [17]. The immediate-release formulation of gabapentin, an anticonvulsant, was approved by the US Food and Drug Administration (FDA) for the treatment of PHN in 2002. It needs to be administered three times daily (tid) due to its nonlinear pharmacokinetics [18], and the rates of dizziness and somnolence are relatively high (28 and $21 \%$, respectively) [19], which may contribute to difficulty attaining efficacious and tolerable dosages. In a retrospective database analysis of patients with PHN who took gabapentin tid, only $14 \%$ of patients reached the recommended therapeutic $1,800 \mathrm{mg} /$ day dosage in, on average, 10 weeks [20].

A gastroretentive formulation of gabapentin (G-GR, Gralise $^{\circledR}$, Depomed Inc., Newark, CA, USA) was subsequently approved for treatment of PHN [21]. G-GR uses a polymer-based technology that, following oral administration with a meal, causes the tablet to swell to a size that promotes gastric retention $[22,23]$. By being retained in the stomach for up to $10 \mathrm{~h}$, the tablet gradually releases gabapentin, which optimizes absorption by its transporters, located predominantly in the upper small intestine, which permits once-daily dosing and better titration to therapeutic dosages.

Safety and efficacy of this new, once-daily formulation in PHN were evaluated in two placebo-controlled, doubleblind, phase III studies [24, 25]. The two studies included a 2-week titration to $1,800 \mathrm{mg} /$ day, followed by 8 weeks of stable dosing at $1,800 \mathrm{mg} / \mathrm{day}$, and then 1 week of dose tapering. Over $90 \%$ of patients in the G-GR group completed the titration period in both studies [26, 27]. The initial 11-week, randomized, double-blind, placebo-controlled, multicenter clinical trial compared G-GR administered once daily $(1,800 \mathrm{mg}$ with the evening meal), or as an asymmetric dose $(1,200 \mathrm{mg} \mathrm{PM} / 600 \mathrm{mg}$ AM, with a meal) with placebo in patients with PHN persisting for at least 3 months following healing of $\mathrm{HZ}$ rash [24]. Compared with placebo, the average daily pain (ADP) score for patients in the G-GR arm decreased more, but the overall changes in the primary endpoint were not statistically significant. This was attributed to a large placebo-response rate, especially among patients whose rash had resolved within less than 6 months prior to study entry ( $\sim 20 \%$ of the study population). Given this finding, the subsequent 11-week, phase III study limited eligibility to patients whose PHN had persisted for at least 6 months following healing of the $\mathrm{HZ}$ rash, and patients were randomized to receive G-GR $(1,800 \mathrm{mg})$ or matching placebo once daily with the evening meal [25]. In that study, there was a significantly greater reduction in ADP score from baseline in the G-GR group compared with placebo $(p=0.013)$, from week 1 and throughout the rest of the study [20].

To gain further insight into the safety, tolerability, and efficacy of G-GR for the treatment of elderly patients with PHN, we analyzed integrated data from the two phase III studies of $1,800 \mathrm{mg} \mathrm{G}-\mathrm{GR}$ versus placebo taken once daily with dinner by age ( $<75$ and $\geq 75$ years).

\section{Methods}

\subsection{Patients}

Data for patients stratified by age ( $<75$ and $\geq 75$ years) were obtained from two multicenter, randomized, placebo-controlled, phase III PHN studies (study 81-0045, clinicaltrial.gov identifier: NCT00335933 and study 81-0062, clinicaltrial.gov identifier: NCT00636636) that were designed to assess the safety and efficacy of G-GR in patients with PHN. These studies have been previously described in detail $[24,25]$. The study protocols were approved by a central institutional review board and were 
conducted in accordance with the International Conference on Harmonization Guidelines for Good Clinical Practice. To be eligible for inclusion, adult patients with a diagnosis of PHN and an average numeric pain rating scale score of $\geq 4$ were eligible if $\geq 3$ months (study 81-0045) or $\geq 6$ months (study 81-0062) had elapsed since healing of the HZ rash. Patients were excluded if they had previously failed to respond to treatment with gabapentin tid $(\geq 1,200 \mathrm{mg} /$ day $)$ or pregabalin ( $\geq 300 \mathrm{mg} /$ day), had experienced dose-limiting adverse events (AEs) with gabapentin tid, or had hypersensitivity to gabapentin. Concomitant medications-tricyclic or selective serotonin reuptake inhibitor antidepressants, acetaminophen (up to $4 \mathrm{~g} /$ day); non-steroidal antiinflammatory drugs (NSAIDs), and aspirin (up to $325 \mathrm{mg} /$ day) — taken at stable doses for $\geq 30$ days prior to screening were allowed only at their stable doses throughout the study to minimize their effect on the G-GR efficacy and safety assessments. Signed, written informed consent was obtained from each patient or their authorized representative prior to study participation. The 138 patients randomized in study 81-0045 to receive G-GR as an asymmetrically divided dose $(1,200 \mathrm{mg}$ PM/ $600 \mathrm{mg}$ AM) were not included in the dataset used for the current analyses.

\subsection{Study Design}

The two studies shared the same basic design, which included a 1-week baseline period followed by a 2 -week titration period, an 8-week stable dose treatment period, and a 1-week dose-tapering period. Doses were increased to a daily dose of $1,800 \mathrm{mg}$ during the 2 -week titration period using a set schedule: day $1=300 \mathrm{mg}$; day $2=$ $600 \mathrm{mg}$; days $3-6=900 \mathrm{mg}$; days $7-10=1,200 \mathrm{mg}$; days $11-14=1,500 \mathrm{mg}$; day $15=1,800 \mathrm{mg}$. Patients continued on a stable dose of $1,800 \mathrm{mg} /$ day for an additional 8 weeks, followed by a 1 -week dose-tapering period. All doses were taken once daily with the evening meal.

Each morning, from the beginning of baseline to the end of the efficacy treatment period (treatment week 10), patients recorded their pain intensity during the previous $24 \mathrm{~h}$ and sleep interference caused by pain in an electronic diary (DiaryPRO, invivodata, Inc., Pittsburgh, PA, USA). For pain intensity, scoring utilized an 11-point numerical rating scale (NRS; where $0=$ no pain, $10=$ worst possible pain); sleep interference scoring utilized the same 11-point NRS (where $0=$ no interference, $10=$ worst possible interference). Assessments for the Patient Global Impression of Change (PGIC) and a neurological examination were completed at week 10 or at early termination.

\subsection{Efficacy Outcomes}

Efficacy parameters included the absolute change and percent change in ADP score on the 11-point NRS from baseline to week 10, the proportion of responders (defined as those patients achieving $30 \%$ or more reduction in ADP from baseline to week 10), the proportion of patients categorized as "Much" or "Very much" improved on the PGIC, and the absolute change and percent change in average daily sleep interference score (SIS) on the 11-point NRS from baseline to week 10 . The integrated analysis was based on the modified intent-to-treat (mITT) population that consisted of all patients aged $<75$ and $\geq 75$ who received any study treatment and had valid baseline efficacy measures.

\subsection{Safety Outcomes}

Safety assessments included the incidence of AEs, serious AEs (SAEs), clinical laboratory assessments, vital signs, and the use of concomitant medications. AEs were coded using the Medical Dictionary for Regulatory Activities (MedDRA; Version 9.0). The number and percentage of patients reporting one or more AEs were categorized by $\mathrm{AE}$ preferred term and $\mathrm{AE}$ system organ class, and summarized by treatment group. The safety analyses were performed on the population consisting of all patients aged $<75$ or $\geq 75$ years who received at least one dose of study drug.

\subsection{Statistical Methods}

Statistical analyses were performed using SAS (Cary, NC, USA) software, version 9.1.3 or higher. Mean percentage changes and mean absolute changes in ADP scores and in average daily SIS from baseline to week 10 were analyzed using an analysis of covariance (ANCOVA) model that included treatment and center factors, and baseline score as covariates. Missing post-treatment scores were imputed using a last-observation-carried-forward (LOCF) approach. The percentage of responders and the percentage of patients feeling "Much" or "Very much" improved were compared between treatment groups using a $z$-test.

\section{Results}

\subsection{Characteristics of Study Population}

A total of 723 patients $(531$ aged $<75$ years [G-GR $=259$; placebo $=272]$ and 192 aged $\geq 75$ years $[\mathrm{G}-\mathrm{GR}=100$; placebo $=92]$ ) were included in the safety population, and 
719 patients (527 aged $<75$ years [G-GR $=256$; placebo $=271]$ and all patients $\geq 75$ years) were included in the efficacy population. Patient demographics and baseline disease characteristics were largely similar for patients in the two age groups (Table 1). The majority of patients were female and Caucasian. The mean age was 61.5 years for the $<75$-year subgroup and 79.3 years for the $\geq 75$-year subgroup. The mean ADP scores at baseline were 6.4 for the $<75$-year subgroup and 6.8 for the $\geq 75$-year subgroup. The only significant difference in baseline characteristics between the subgroups was that older patients had reduced renal function. Based on calculated creatinine clearance rates (using the Cockroft-Gault method), patients $\geq 75$ years had a mean (standard deviation [SD]) creatinine clearance of $65.4(13.7) \mathrm{ml} / \mathrm{min}$ versus $95.6(48.0) \mathrm{ml} / \mathrm{min}$ for patients $<75$ years (Table 1 ).

\subsection{Titration, Adherence, and Study Completion}

The majority of patients was titrated to the effective dosage $(1,800 \mathrm{mg} /$ day $)$ within 2 weeks and the rates were similar between the age subgroups $(94.6 \%$ for $<75$ years and $96.0 \%$ for $\geq 75$ years). Most patients completed the study and, when stratified by age, slightly more patients in the older subgroup completed the study $(88.0 \%$ for the $\geq 75$ years subgroup and $81.9 \%$ for the $<75$-years subgroup). Overall adherence to the treatment regimen was high (placebo $98.5 \%$, G-GR $99.2 \%$ ).

\subsection{Efficacy}

At week 10, the percent change from baseline in ADP with G-GR was significantly greater for both age groups compared with placebo (Fig. 1a). For patients aged $\geq 75$ years, the change in ADP was $-21.9 \%$ (95\% CI -30.5 to -13.3 ) for placebo versus $-34.2 \%$ (95\% CI -41.7 to $-21.9)$ for G-GR $(p=0.0348)$. For patients $<75$ years of age, the change in ADP was $-29.9 \%(95 \% \mathrm{CI}-35.2$ to $-24.6)$ for placebo versus $-38.3 \%$ (95\% CI -43.5 to $-33.1)$ for G-GR $(p=0.0079)$. Compared with placebo, the mean difference in ADP was $-7.8 \%$ in favor of G-GR (95\% CI -12.9 to -2.8 ) (Fig. 1b). When stratified by age,
Table 1 Demographics and baseline characteristics, efficacy population
${ }^{\text {a }}$ Creatinine clearance as calculated by the CockroftGault method

${ }^{\mathrm{b}}$ Data not available for some patients

${ }^{c}$ Patients may be reported in more than one category

$B M I$ body mass index, $S D$ standard deviation, $H Z$ herpes zoster

\begin{tabular}{|c|c|c|c|}
\hline & $\begin{array}{l}\text { Total } \\
(n=719)\end{array}$ & $\begin{array}{l}<75 \text { years } \\
(n=527)\end{array}$ & $\begin{array}{l}\geq 75 \text { years } \\
(n=192)\end{array}$ \\
\hline Age (years), mean (SD) & $66.2(12.3)$ & $61.5(10.8)$ & $79.3(3.4)$ \\
\hline Range & $21-89$ & $21-74$ & $75-89$ \\
\hline \multicolumn{4}{|l|}{ Sex, $n(\%)$} \\
\hline Female & $411(57.2)$ & 309 (58.6) & $102(53.1)$ \\
\hline Male & $308(42.8)$ & $218(41.4)$ & $90(46.9)$ \\
\hline \multicolumn{4}{|l|}{ Race, $n(\%)$} \\
\hline Caucasian & $637(88.6)$ & $462(87.7)$ & $175(91.1)$ \\
\hline Other & $82(11.4)$ & $65(12.3)$ & $17(8.9)$ \\
\hline Weight $(\mathrm{kg})$, mean $(\mathrm{SD})$ & $81.2(17.9)$ & $82.4(18.9)$ & $78.1(14.6)$ \\
\hline BMI $\left(\mathrm{kg} / \mathrm{m}^{2}\right)$, mean $(\mathrm{SD})$ & $28.8(5.6)$ & $29.1(5.9)$ & $27.9(4.7)$ \\
\hline \multicolumn{4}{|l|}{ Creatinine clearance $^{\mathrm{a}, \mathrm{b}}(\mathrm{ml} / \mathrm{min})$} \\
\hline Mean (SD) & $87.5(44.0)$ & $95.6(48.0)$ & $65.4(13.7)$ \\
\hline$<80 \mathrm{ml} / \mathrm{min}, n(\%)$ & $349(48.5)$ & $189(35.9)$ & $160(83.3)$ \\
\hline$\geq 80 \mathrm{ml} / \mathrm{min}, n(\%)$ & $352(49.0)$ & $322(61.1)$ & $30(15.6)$ \\
\hline \multicolumn{4}{|l|}{ Average Daily Pain Score } \\
\hline Mean (SD) & $6.5(1.4)$ & $6.4(1.4)$ & $6.8(1.4)$ \\
\hline Months since $\mathrm{HZ}$ resolution ${ }^{\mathrm{b}}$, mean (SD) & $27.9(36.0)$ & $26.1(36.9)$ & $32.8(32.8)$ \\
\hline$<6$ months, $n(\%)$ & $68(9.5)$ & $54(10.2)$ & $14(7.3)$ \\
\hline 6-12 months, $n(\%)$ & $197(27.4)$ & $157(29.8)$ & $40(20.8)$ \\
\hline$>12$ months, $n(\%)$ & $449(62.4)$ & $311(59.0)$ & $138(71.9)$ \\
\hline \multicolumn{4}{|l|}{ Location of neuropathic pain ${ }^{\mathrm{c}}, n(\%)$} \\
\hline Face & $152(21.1)$ & $104(19.7)$ & $48(25.0)$ \\
\hline Anterior torso & $291(40.5)$ & $218(41.4)$ & $73(38.0)$ \\
\hline Posterior torso & $295(41.0)$ & $218(41.4)$ & $77(40.1)$ \\
\hline Arms & $68(9.5)$ & $44(8.3)$ & $24(12.5)$ \\
\hline Legs & $49(6.8)$ & $35(6.6)$ & $14(7.3)$ \\
\hline Other & $150(20.9)$ & $119(22.6)$ & $31(16.1)$ \\
\hline
\end{tabular}



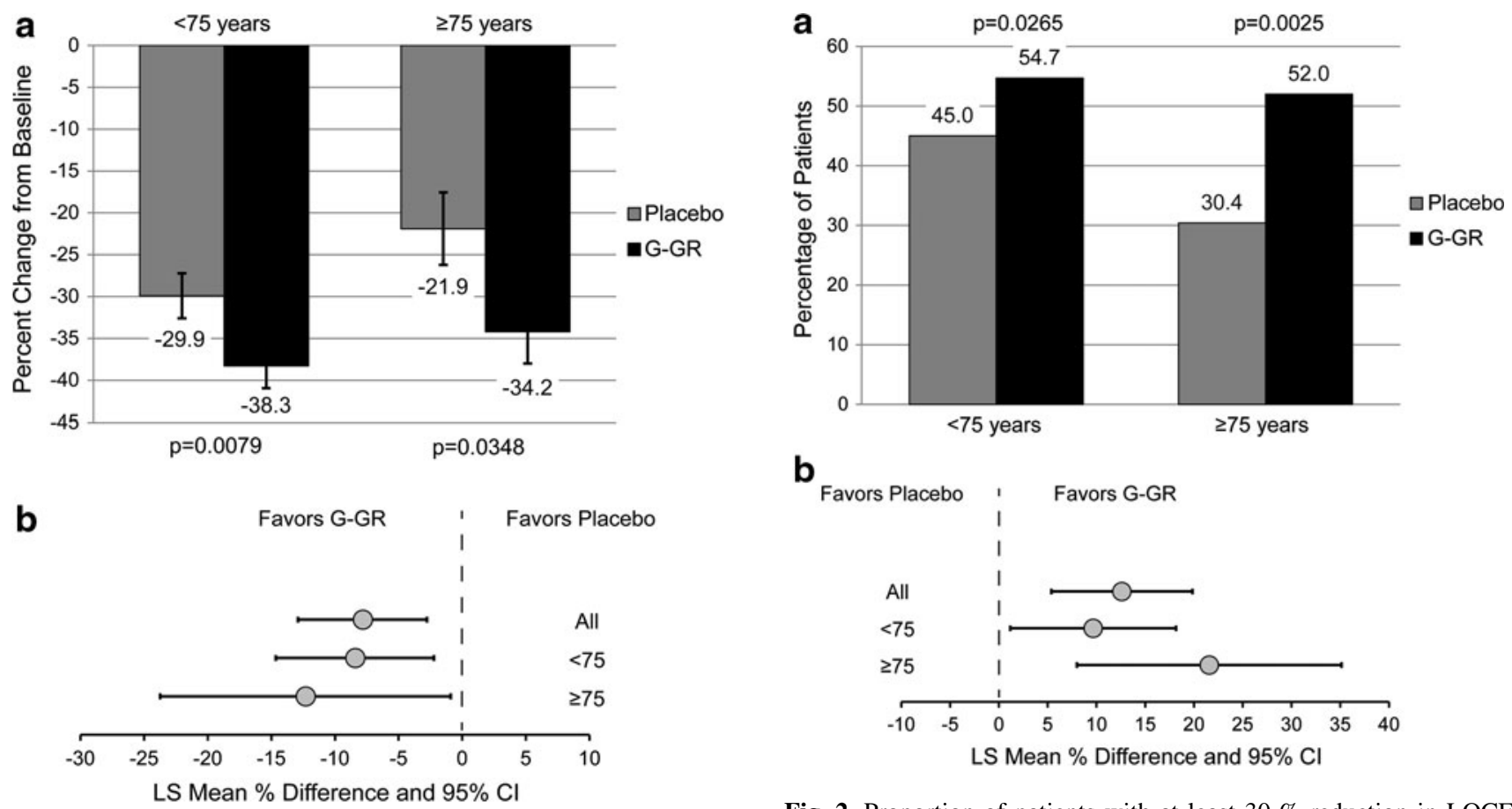

Fig. 1 Reduction in ADP score at week 10. a Percent change from baseline. $p$-Value is for the test of difference in the LS mean percent change from baseline between the two G-GR age groups and their respective placebo based on the ANCOVA model that includes treatment and center factors, and baseline pain score as a covariate. b Forest plot for LS mean difference in ADP. ADP average daily pain, $A N C O V A$ analysis of covariance, $G-G R$ gastroretentive gabapentin, $L S$ least square

the mean difference in ADP was similar between patients $\geq 75$ years (difference between G-GR and placebo, $-12.3 \%$; $95 \% \mathrm{CI}-23.7$ to -0.9$)$ and patients $<75$ years (difference between G-GR and placebo, $-8.4 \%$; $95 \%$ CI -14.7 to -2.2 ).

At week 10 , significantly more G-GR- than placebotreated patients in both age subgroups had $\geq 30 \%$ reduction in ADP (placebo/G-GR): $30.4 / 52.0 \%$ for $\geq 75$ years and $45.0 / 54.7 \%$ for $<75$ years (Fig. 2a). More G-GR patients $\geq 75$ years had $\geq 30 \%$ reduction in ADP in comparison with placebo (difference between G-GR and placebo, $21.6 \%$; $95 \%$ CI 8.0-35.1; $p=0.0025$ ) than patients $<75$ years of age (difference between G-GR and placebo, $9.7 \%$; $95 \%$ CI 1.2-18.2; $p=0.0265$ ) (Fig. 2b).

Compared with placebo, the mean absolute change from baseline in average daily SIS was also significantly improved in patients in the G-GR group: -1.3 versus -2.4 $(p=0.0017)$ for $\geq 75$ years and -1.8 versus -2.7 $(p<0.0001)$ for $<75$ years (Fig. 3a). As for ADP scores, the mean difference in SIS between G-GR and placebo groups was similar between older and younger patients ( $\geq 75$ years: difference $-1.1,95 \% \mathrm{CI}-1.8$ to -0.4 vs. $<75$ years: difference $-0.8,95 \% \mathrm{CI}-1.2$ to -0.5 ) (Fig. 3b).

Fig. 2 Proportion of patients with at least $30 \%$ reduction in LOCF ADP score at week 10. a Percentage of patients. $p$-Value is the test for treatment effect between the two G-GR age groups and their respective placebo based on the $z$ test for the difference in proportions between two groups. b Forest plot for LS mean difference in ADP responders. $A D P$ average daily pain, $G-G R$ gastroretentive gabapentin, $L O C F$ last observation carried forward, $L S$ least square

Similar numbers of patients $\geq 75$ years of age receiving G-GR considered themselves "Much" or "Very much" improved on the PGIC compared with patients $<75$ years of age (Fig. 4). For $\geq 75$ years, $35.0 \%$ of patients treated with G-GR felt "Much" or "Very much" improved in comparison with $20.7 \%$ of patients receiving placebo (difference $14.4 \%, 95 \%$ CI $1.9-26.8 ; p=0.0272$ ). For $<75$ years, $44.9 \%$ of patients treated with G-GR considered themselves "Much" or "Very much" improved compared with $33.6 \%$ of patients receiving placebo (difference $11.3 \%, 95 \%$ CI $3.1-19.6 ; p=0.0077)$.

\subsection{Safety}

Similar numbers of patients aged $\geq 75$ years reported at least one $\mathrm{AE}$ compared with patients $<75$ years, and in both groups, more AEs were reported for the G-GR arm than the placebo arm (placebo/G-GR): $\geq 75$ years $(47.8 /$ $56.0 \%),<75$ years $(41.2 / 53.7 \%)$ (Table 2). In patients $\geq 75$ years, the AEs that occurred most frequently (placebo/G-GR) were dizziness (3.3/12.0\%), nausea $(1.0 / 5.4 \%)$, somnolence $(0 / 5.0 \%)$, diarrhea $(2.2 / 5.0 \%)$, peripheral edema $(0 / 4.0 \%)$, and urinary tract infections $(0 / 3.0 \%)$. In patients $<75$ years, these AEs were reported at a similar frequency (placebo/G-GR): dizziness 


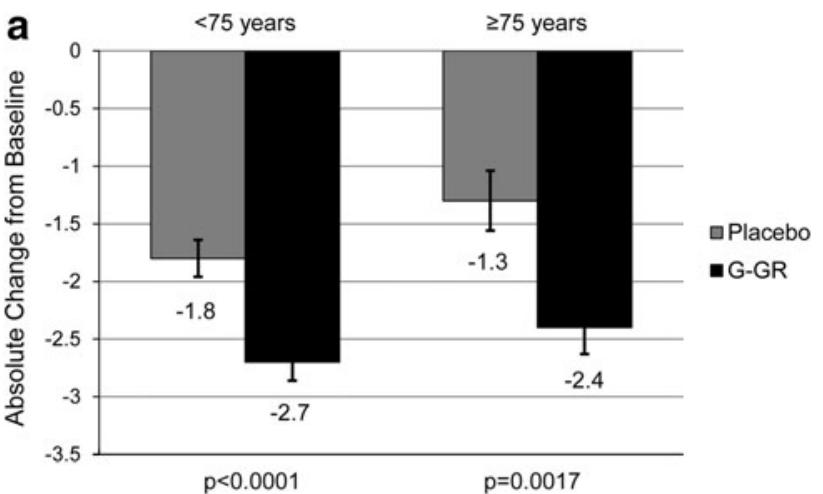

b

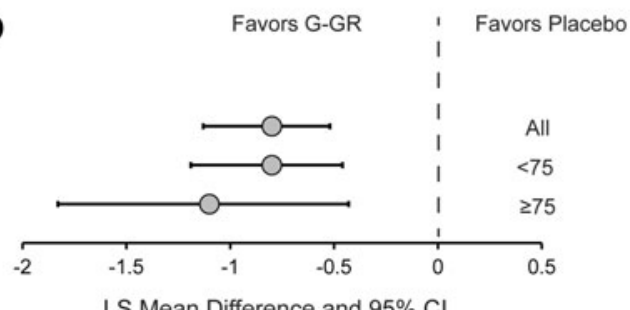

Fig. 3 Reduction in average daily SIS. a LS mean (SEM) absolute change by age subgroup. $p$-Value is for the test of difference in the LS mean absolute change from baseline between G-GR age groups and their respective placebo groups based on the ANCOVA model that includes treatment and center factors, and baseline pain score as a covariate. b Forest plot for LS mean difference in SIS. ANCOVA analysis of covariance, $G-G R$ gastroretentive gabapentin, $L S$ least square, SEM standard error of the mean, SIS sleep interference score

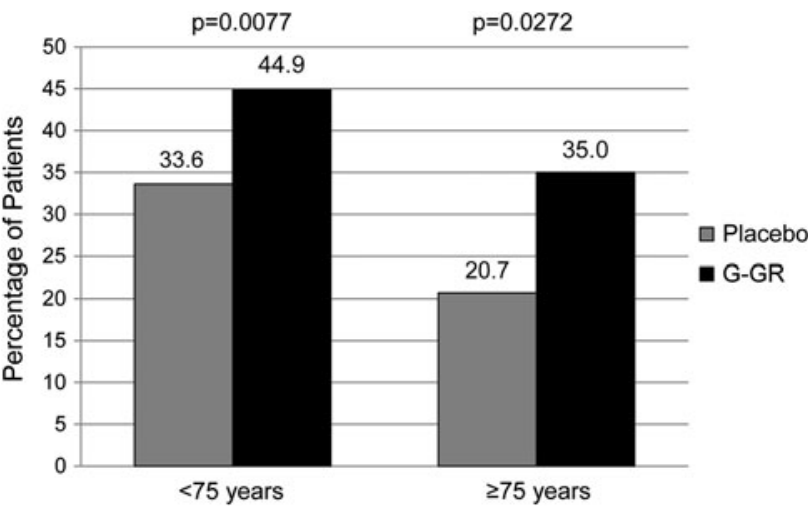

Fig. 4 Percentage of patients who reported feeling "Much" or "Very Much" improved on Patient Global Impression of Change. $p$-Value for the test of treatment effect between G-GR age groups and their respective placebo groups is based on the $z$ test for the difference in proportions between two groups. $G-G R$ gastroretentive gabapentin

$(1.8 / 10.4 \%)$, nausea $(2.9 / 4.2 \%)$, somnolence $(3.7 / 4.2 \%)$, diarrhea $(2.9 / 2.7 \%)$, peripheral edema $(0.4 / 3.9 \%)$, and urinary tract infections $(0.7 / 1.2 \%$ ) (Table 2$)$. The prevalence of all AEs, including the most common for gabapentinoids (dizziness and somnolence), decreased rapidly during the 2-week titration period and reached sustained low levels after approximately 4-5 weeks of treatment (Fig. 5). For patients aged $\geq 75$ years, study discontinuations due to AEs were more frequent in the G-GR group than in the placebo group ( 9.0 vs. $5.4 \%)$. For patients aged $<75$ years, discontinuation rates due to AEs were lower for G-GR than for placebo (6.3 vs. $10.0 \%$ ).

There was no significant difference between both age subgroups in reporting SAEs (Table 2). For $<75$ years, SAEs were experienced by eight $(2.9 \%)$ patients in the placebo group and six (2.3\%) patients in the G-GR group. For $\geq 75$ years, three $(3.3 \%)$ patients in the placebo group and two $(2.0 \%)$ patients in the G-GR group experienced SAEs. None of the SAEs were considered by investigators to be related to study drug. Two deaths occurred in the placebo group (one in each age subgroup), both from myocardial infarction. No clinically significant changes in vital signs, weight, or laboratory parameters were noted.

\section{Discussion}

Elderly patients, who account for the demographic subgroup at highest risk for developing PHN, represent the fastest-growing segment of the population in Western countries [9]. Although the vaccine $\left(Z_{0}\right.$ stavax ${ }^{\circledR}$, Merck, Whitehouse Station, NJ, USA) effective at preventing HZ and PHN [28] has been available for patients $\geq 60$ years since 2006, and for patients $\geq 50$ years since 2011 [29], only approximately $8 \%$ of adults aged $\geq 60$ years reported having had the vaccination by 2011 [30]. Given that the incidence and prevalence of PHN is expected to increase in the elderly population, and that PHN can be a huge burden and have a significant effect on the quality of life of elderly patients [31], this is concerning.

Whether vaccinated or not, for elderly patients who develop PHN, co-morbidities and polypharmacy are common and should be taken into account when prescribing medications. Drugs commonly used to treat PHN, including tricyclic antidepressants and serotonin-norepinephrine reuptake inhibitors, gabapentin and pregabalin, and opioids, are each associated with AEs that may be especially problematic in frail or vulnerable elderly patients [32]. Tricyclic antidepressant therapy for PHN in the elderly is generally avoided because it is contraindicated or is poorly tolerated (e.g., excessive sedation, cognitive impairment, constipation, dry mouth, and orthostatic hypotension) [33]. Opioid analgesics are considered effective as second-line medications, but because the half-life of the active drugs and their metabolites are increased in the elderly, it is recommended that dosages be reduced, dose frequency be reduced, and that creatinine clearance be monitored [32, 34]. In addition, opioids may be problematic for elderly patients as they cause constipation, cognitive impairment, 
Table 2 Summary of adverse events, safety population

\begin{tabular}{|c|c|c|c|c|}
\hline \multirow[t]{2}{*}{ Preferred term, $n(\%)$} & \multicolumn{2}{|l|}{$<75$ years } & \multicolumn{2}{|l|}{$\geq 75$ years } \\
\hline & Placebo $(n=272)$ & G-GR $(n=259)$ & Placebo $(n=92)$ & G-GR $(n=100)$ \\
\hline Patients with $\geq 1 \mathrm{AE}$ & $112(41.2)$ & $139(53.7)$ & $44(47.8)$ & $56(56.0)$ \\
\hline$\geq 1 \mathrm{AE}$ leading to study discontinuation & $26(10.0)$ & $17(6.3)$ & $5(5.4)$ & $9(9.0)$ \\
\hline$\geq 1$ SAEs & $8(2.9)$ & $6(2.3)$ & $3(3.3)$ & $2(2.0)$ \\
\hline \multicolumn{5}{|l|}{$\mathrm{AEs}^{\mathrm{a}}$} \\
\hline Dizziness & $5(1.8)$ & $27(10.4)$ & $3(3.3)$ & $12(12.0)$ \\
\hline Nausea & $8(2.9)$ & $11(4.2)$ & $1(1.0)$ & $5(5.4)$ \\
\hline Headache & $11(4.0)$ & $14(5.4)$ & $4(4.3)$ & $1(1.0)$ \\
\hline Somnolence & $10(3.7)$ & $11(4.2)$ & 0 & $5(5.0)$ \\
\hline Diarrhea & $8(2.9)$ & $7(2.7)$ & $2(2.2)$ & $5(5.0)$ \\
\hline Edema, peripheral & $1(0.4)$ & $10(3.9)$ & 0 & $4(4.0)$ \\
\hline Dry mouth & $4(1.5)$ & $8(3.1)$ & $1(1.1)$ & $2(2.0)$ \\
\hline Urinary tract infection & $2(0.7)$ & $3(1.2)$ & 0 & $3(3.0)$ \\
\hline Nasopharyngitis & $8(2.9)$ & $7(2.7)$ & $1(1.1)$ & $2(2.0)$ \\
\hline Weight increased & $1(0.4)$ & $7(2.7)$ & $1(1.1)$ & 0 \\
\hline Constipation & $1(0.4)$ & $3(1.2)$ & 0 & $2(2.0)$ \\
\hline Herpes zoster & $3(1.1)$ & $2(0.8)$ & $1(1.1)$ & $2(2.0)$ \\
\hline Pneumonia & 0 & $1(0.4)$ & 0 & $2(2.0)$ \\
\hline Pain in extremity & $1(0.4)$ & $5(1.9)$ & $1(1.1)$ & $2(2.0)$ \\
\hline Rash & $4(1.5)$ & $1(0.4)$ & 0 & $2(2.0)$ \\
\hline Blood urea increased & 0 & 0 & 0 & $2(2.0)$ \\
\hline Sedation & 0 & 0 & 0 & $2(2.0)$ \\
\hline
\end{tabular}

${ }^{a}$ Includes events reported for $\geq 2 \%$ of patients in any group

$A E$ adverse event, $G-G R$ gastroretentive gabapentin, $S A E$ serious adverse event

dizziness, and may lead to an increased risk of hip fracture $[34,35]$. Also, they are more likely to lead to drug-drug interactions in elderly patients who are frequently taking medications (e.g., beta-blockers, statins, selective serotonin reuptake inhibitors, NSAIDs, proton pump inhibitors, and sedative hypnotics) that are metabolized by the same cytochrome P450 (CYP) enzymes [36]. Gabapentin is an attractive treatment option for older patients due to its low propensity for drug-drug interactions, as it is not metabolized by the CYP system drug-metabolizing enzymes, but absorbed by a saturable L-amino acid transporter in the upper small intestine and renally excreted [37]. The fact that gabapentin is excreted by the kidneys and not metabolized also means that physiological changes associated with aging that effect drug absorption, metabolism, volume of distribution, plasma concentration, and drug bioavailability are not an issue for gabapentin, but dosages should be adjusted in patients with renal impairment. However, despite these benefits, for the immediate-release formulation of gabapentin, the tid dosing regimen due to gabapentin's short half-life results in the saturation of L-amino acid transporters and nonlinear pharmacokinetics, and the rapid rise in gabapentin plasma levels after each dose is associated with a high incidence of common AEs [18, 19], all of which may be especially bothersome for the elderly. Thus, effective and well tolerated therapy with improved pharmacokinetics, simpler dosing, and reduced AEs with once-daily G-GR may provide a needed therapeutic option for elderly patients with PHN.

Gastroretentive technology used in the formulation of G-GR allows convenient once-daily dosing and for patients to reach the recommended dosage of $1,800 \mathrm{mg} /$ day within 2 weeks [21, 23]. Upon contact with gastric juices, G-GR tablets immediately begin to swell to 3-4 times their original size and slowly release gabapentin. When taken with meals, the tablets are retained in the stomach for approximately $8-9 \mathrm{~h}$ and provide a steady and continuous delivery of gabapentin to its site of absorption. This gradual and steady release of gabapentin reduces the likelihood of the L-amino acid transporters being saturated, and results in improved pharmacokinetics, better dose proportionality and bioavailability, and consequently simpler dosing and more rapid titration to an effective dosage for G-GR compared with immediate-release gabapentin tid [21, 23].

In the current analysis of G-GR in patients with PHN, almost all elderly patients $\geq 75$ years $(96 \%)$ were able to 

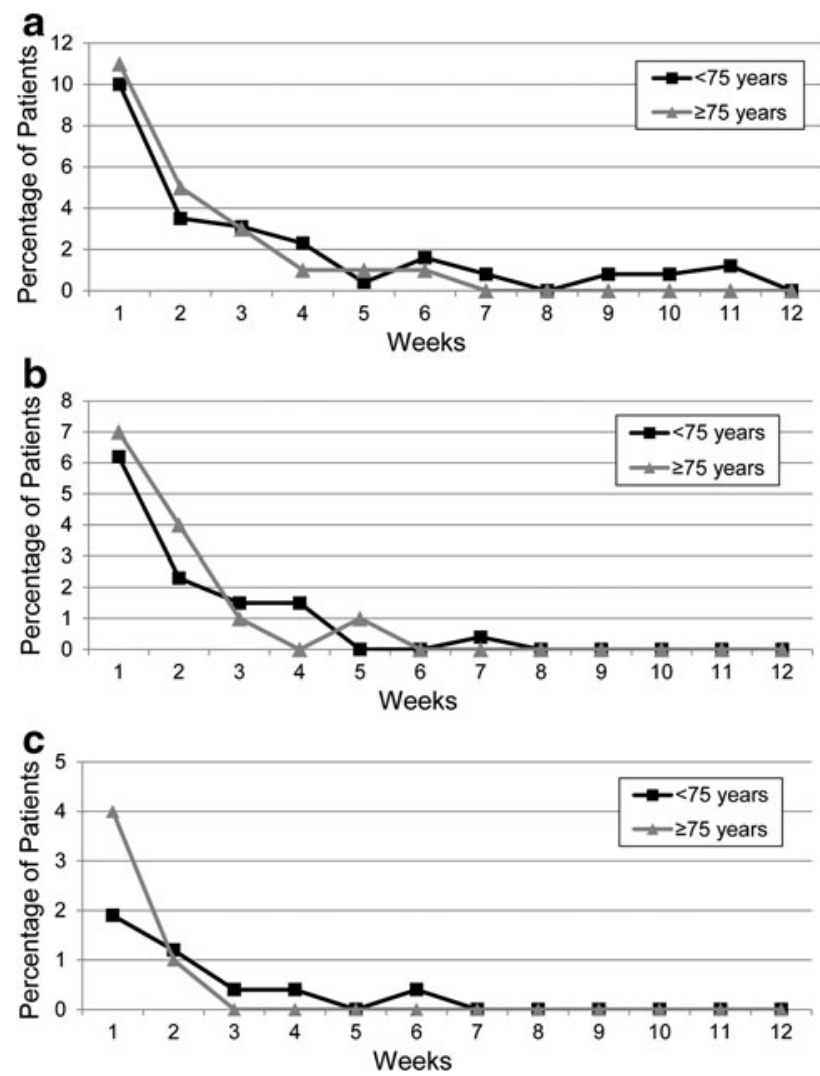

Fig. 5 Adverse events over 12 weeks. a All adverse events. b Dizziness. c Somnolence

tolerate the titration schedule and reach the therapeutic dosage of $1,800 \mathrm{mg} /$ day G-GR within 2 weeks. This is in contrast with results obtained from a retrospective analysis of PHN patients treated with gabapentin tid, which showed that only $14 \%$ of patients were able to attain a daily dosage of $1,800 \mathrm{mg}$ and that, for those who did, it took over 2 months [20]. In addition to the simplified dosing and shorter titration to an efficacious dosage, G-GR showed good efficacy, regardless of patient age or renal function. For elderly patients ( $\geq 75$ years), treatment with the oncedaily G-GR formulation significantly reduced the mean ADP scores to levels similar to those for younger patients when compared with placebo, and which were comparable to those previously observed for the overall study population [24-27]. For a pain decrease that is considered clinically meaningful [38], more elderly than younger patients (21.6 vs. $9.7 \%$ above placebo) had at least a $30 \%$ reduction in ADP at week 10. Based on the results from the SIS measured on the same NRS widely used to assess pain [39], elderly patients taking G-GR recorded reductions in SIS similar to those for younger patients. Sleep disturbance is a major problem that complicates disease management in patients with PHN [40], and combination of G-GR effect on both pain and sleep disturbance may have a better effect on patient function itself. Consistent with this idea, for the overall effect of the G-GR treatment, similar percentages of elderly and younger patients reported feeling "Much" or "Very much" improved (14.4 vs. $11.3 \%$, respectively) when compared with placebo.

The safety profile of G-GR established in two phase III clinical trials in patients with PHN generally extended to the subgroup of patients $\geq 75$ years, supporting the notion that tolerability of G-GR is not affected by age of the patient. In previous integrated analyses of phase III clinical trials, dizziness, somnolence, headache, and peripheral edema were the most commonly reported AEs for the entire study population receiving G-GR $(n=359)$, and a subgroup analysis revealed a slightly higher incidence of peripheral edema in patients $\geq 65$ years $(5.3 \%)$ compared with patients aged $\leq 65$ years of age $(1.5 \%)$ [26]. In the current subgroup analysis of AEs by age, the most common AEs reported by patients aged $\geq 75$ years included dizziness and somnolence, but also nausea, and the rates of occurrence were similar to those for patients aged $<75$ years. The analysis revealed a similar occurrence of peripheral edema between patients $\geq 75$ and $<75$ years, whereas diarrhea was reported more often and headache less often by patients $\geq 75$ years. Furthermore, all AEs associated with G-GR, including the most commonly reported AEs for gabapentinoids (dizziness and somnolence), decreased rapidly to sustained low levels after 3-5 weeks of treatment for all patients, regardless of their age. Finally, the rate of study discontinuation due to AEs for the G-GR group was very similar for older and younger patients $(\sim 9.5 \%)$.

Although no direct comparisons have been made between G-GR and gabapentin tid, the incidences of the most common gabapentinoid-related AEs (dizziness and somnolence) are lower for patients receiving G-GR. A placebo-controlled trial of gabapentin tid that used 1,800 or $2,400 \mathrm{mg} /$ day [41], or up to $3,600 \mathrm{mg} /$ day [42], reported rates of dizziness from 24 to $33 \%$, and rates of somnolence from 17 to $27 \%$. In contrast, G-GR rates of dizziness and somnolence reported for patients $\geq 75$ years of age were 12 and $5 \%$, respectively. Better tolerability of the gastroretentive formulation may be due to more gradual elevation in serum levels of gabapentin compared with the immediate-release formulation. It could also result in part from the G-GR treatment regimen (once daily with the evening meal), when peak gabapentin concentrations occur during the period when most patients are asleep.

Limitations of this study include the short duration of stable gabapentin treatment ( 8 weeks), which allowed only short-term assessments of safety and efficacy, and the exclusion of patients with PHN who had either previously not responded to gabapentin or pregabalin, or had doselimiting adverse effects preventing titration of gabapentin 
to an effective dose. Although these exclusion criteria may have resulted in an enriched patient population, this is how all clinical studies of gabapentin have been conducted, as it was not considered ethical to treat patients with a drug they could not tolerate or that did not provide therapeutic benefit.

\section{Conclusion}

The complexity of medical conditions and the use of medications to treat those conditions increase with age, providing the potential for drug interaction and more bothersome AEs that impact the patient's quality of life. Once-daily G-GR $(1,800 \mathrm{mg}$ with the evening meal) reduced pain from PHN, and improved sleep and overall quality of life for elderly patients with PHN (aged $\geq 75$ years) to the same levels as for younger patients (aged $<75$ years). The occurrence and patterns of AEs in the elderly were also comparable to those in younger patients, without increased risks for common AEs and with no additional safety signals. These results support the notion that both the drug efficacy and the relative risks for the commonly observed AEs with G-GR are not affected by increasing age or decreasing renal function. The clinically meaningful reductions in pain, coupled with the favorable tolerability profile of G-GR, its lack of significant interactions with other drugs, its convenient dosing, and ease of rapid titration to an efficacious dosage, make G-GR a valuable addition to PHN treatment in elderly patients.

Acknowledgments This study was supported by Depomed Inc., Newark, CA, USA. Iwona Bucior, Ph.D. and Stephanie Kareht, Ph.D. of Depomed provided medical writing support. Michael Zhang provided assistance with biostatistics.

Authors' contributions AG and SL contributed to the conception, data interpretation, and drafting of the manuscript, and/or revising of the manuscript for important intellectual content. AG and SL are responsible for the work described in this paper, and provided final approval of the version to be published.

Open Access This article is distributed under the terms of the Creative Commons Attribution Noncommercial License which permits any noncommercial use, distribution, and reproduction in any medium, provided the original author(s) and the source are credited.

\section{References}

1. Cunningham AL, Dworkin RH. The management of post-herpetic neuralgia. BMJ. 2000;321(7264):778-9.

2. Douglas MW, Johnson RW, Cunningham AL. Tolerability of treatments for postherpetic neuralgia. Drug Saf. 2004;27(15): 1217-33.
3. Niv D, Maltsman-Tseikhin A, Lang E. Postherpetic neuralgia: what do we know and where are we heading? Pain Physician. 2004;7(2):239-47.

4. Insinga RP, Itzler RF, Pellissier JM, et al. The incidence of herpes zoster in a United States administrative database. J Gen Intern Med. 2005;20(8):748-53.

5. Pinchinat S, Cebrian-Cuenca AM, Bricout H, et al. Similar herpes zoster incidence across Europe: results from a systematic literature review. BMC Infect Dis. 2013;13:170.

6. Yawn BP, Saddier P, Wollan PC, et al. A population-based study of the incidence and complication rates of herpes zoster before zoster vaccine introduction. Mayo Clin Proc. 2007;82(11): 1341-9.

7. Johnson RW, Wasner G, Saddier P, et al. Postherpetic neuralgia: epidemiology, pathophysiology and management. Expert Rev Neurother. 2007;7(11):1581-95.

8. Abdulla A, Adams N, Bone M, et al. Guidance on the management of pain in older people. Age Ageing. 2013;42(Suppl. 1):S1-57.

9. Christensen K, Doblhammer G, Rau R, et al. Ageing populations: the challenges ahead. Lancet. 2009;374(9696):1196-208.

10. World Population Data Base [online]. http://www.census.gov/ population/international/data/idb/worldpop.php (Accessed $10 \mathrm{Sep}$ 2013).

11. Persons AGSPoPPiO. The management of persistent pain in older persons. J Am Geriatr Soc. 2002;50 Suppl. 6:S205-24.

12. Fortin M, Bravo G, Hudon C, et al. Prevalence of multimorbidity among adults seen in family practice. Ann Fam Med. 2005;3(3):223-8.

13. Qato DM, Alexander GC, Conti RM, et al. Use of prescription and over-the-counter medications and dietary supplements among older adults in the United States. JAMA. 2008;300(24):2867-78.

14. Ballentine NH. Polypharmacy in the elderly: maximizing benefit, minimizing harm. Crit Care Nurs Q. 2008;31(1):40-5.

15. Gandhi TK, Weingart SN, Borus J, et al. Adverse drug events in ambulatory care. N Engl J Med. 2003;348(16):1556-64.

16. Rastogi R, Meek BD. Management of chronic pain in elderly, frail patients: finding a suitable, personalized method of control. Clin Interv Aging. 2013;8:37-46.

17. Argoff CE. Review of current guidelines on the care of postherpetic neuralgia. Postgrad Med. 2011;123(5):134-42.

18. Stewart BH, Kugler AR, Thompson PR, et al. A saturable transport mechanism in the intestinal absorption of gabapentin is the underlying cause of the lack of proportionality between increasing dose and drug levels in plasma. Pharm Res. $1993 ; 10(2): 276-81$.

19. Pfizer. Neurontin ${ }^{\circledR}$ (gabapentin): prescribing information [online]. http://labeling.pfizer.com/ShowLabeling.aspx?id=630 (Accessed 11 Apr 2013).

20. Johnson P, Becker L, Halpern R, et al. Real-world treatment of post-herpetic neuralgia with gabapentin or pregabalin. Clin Drug Investig. 2013;33(1):35-44.

21. Argoff CE, Chen C, Cowles VE. Clinical development of a oncedaily gastroretentive formulation of gabapentin for treatment of postherpetic neuralgia: an overview. Expert Opin Drug Deliv. 2012;9(9):1147-60.

22. Berner B, Cowles VE. Case studies in swelling polymeric gastric retentive tablets. Expert Opin Drug Deliv. 2006;3(4):541-8.

23. Chen $\mathrm{C}$, Han $\mathrm{CH}$, Sweeney M, et al. Pharmacokinetics, efficacy, and tolerability of a once-daily gastroretentive dosage form of gabapentin for the treatment of postherpetic neuralgia. J Pharm Sci. 2013;102(4):1155-64.

24. Wallace MS, Irving G, Cowles VE. Gabapentin extended-release tablets for the treatment of patients with postherpetic neuralgia: a randomized, double-blind, placebo-controlled, multicentre study. Clin Drug Investig. 2010;30(11):765-76. 
25. Sang CN, Sathyanarayana R, Sweeney M, et al. Gastroretentive gabapentin (G-GR) formulation reduces intensity of pain associated with postherpetic neuralgia (PHN). Clin J Pain. 2013;29(4):281-8.

26. Irving GA, Sweeney M. Tolerability and safety of gastroretentive once-daily gabapentin tablets for the treatment of postherpetic neuralgia. J Pain Res. 2012;5:203-8.

27. Rauck RL, Irving GA, Wallace MS, et al. Once-daily gastroretentive gabapentin for postherpetic neuralgia: integrated efficacy, time to onset of pain relief and safety analyses of data from two phase 3 multicenter, randomized, double-blind, placebo-controlled studies. J Pain Symptom Manage. 2013;46(2):219-28.

28. Gilden D. Efficacy of live zoster vaccine in preventing zoster and postherpetic neuralgia. J Intern Med. 2011;269(5):496-506.

29. Merck. Zostavax ${ }^{\circledR}$ : prescribing information [online]. http://www. merck.com/product/usa/pi_circulars/z/zostavax/zostavax_pi2.pdf (Accessed 22 May 2013).

30. Annunziata K, Rak A, Del Buono $\mathrm{H}$, et al. Vaccination rates among the general adult population and high-risk groups in the United States. PLoS One. 2012;7(11):e50553.

31. Johnson RW, Bouhassira D, Kassianos G, et al. The impact of herpes zoster and post-herpetic neuralgia on quality-of-life. BMC Med. 2010;8:37.

32. Schmader KE, Baron R, Haanpaa ML, et al. Treatment considerations for elderly and frail patients with neuropathic pain. Mayo Clin Proc. 2010;85(3 Suppl. 3):S26-32.

33. American Geriatrics Society Beers Criteria Update Expert Panel. American Geriatrics Society updated Beers Criteria for potentially inappropriate medication use in older adults. J Am Geriatr Soc. 2012;60(4):616-31.
34. Dalacorte RR, Rigo JC, Dalacorte A. Pain management in the elderly at the end of life. N Am J Med Sci. 2011;3(8):348-54.

35. Dworkin RH, Schmader KE. Treatment and prevention of postherpetic neuralgia. Clin Infect Dis. 2003;36(7):877-82.

36. Pergolizzi JV. Quantifying the impact of drug-drug interactions associated with opioids. Am J Manage Care. 2011;17(Suppl. 11):S288-92.

37. Chen C, Cowles VE, Sweeney M. The intestinal absorption mechanism of gabapentin makes it appropriate for gastroretentive delivery. Curr Clin Pharmacol. 2013;8(1):67-72.

38. Farrar JD, Young JPJ, LaMoreaux L, et al. Clinical importance of changes in chronic pain intensity measured on an 11-point numerical pain rating scale. Pain. 2001;94(2):149-58.

39. Dworkin RH, Turk DC, Wyrwich KW, et al. Interpreting the clinical importance of treatment outcomes in chronic pain clinical trials: IMMPACT recommendations. J Pain. 2008;9(2):105-21.

40. Vinik A, Emir B, Cheung R, et al. Relationship between pain relief and improvements in patient function/quality of life in patients with painful diabetic peripheral neuropathy or postherpetic neuralgia treated with pregabalin. Clin Ther. 2013;35(5):612-23.

41. Rice AS, Maton S, Postherpetic Neuralgia Study Group. Gabapentin in postherpetic neuralgia: a randomised, double blind, placebo controlled study. Pain. 2001;94(2):215-24.

42. Rowbotham M, Harden N, Stacey B, et al. Gabapentin for the treatment of postherpetic neuralgia: a randomized controlled trial. JAMA. 1998;280(21):1837-42. 